\title{
The Building of Gender Identity From the Resilience Concepts
}

\author{
Angélica Flores González, Sandra Carina Fulquez \\ Autonomous University of Baja California, Baja California, México
}

\begin{abstract}
The study focuses on the construction of the identity of women participating in a productive program in the Mexicali Valley in Baja California State, Mexico, in situations of violence, from the processes and contents of the resilience approach. Manifest feminine gender as anchor a narrative between their individual identity and social identities intergeneric culture is created and accumulated from codes of gender, to be recursively taught in socialization; derived from them, develop processes of inclusion/exclusion, so that memory is the result of the historical relations of power. However, we noted that the power to deal with problematic or adverse situations responds to different ways that lead to having different styles of coping. From resilience capacity to deal with situations of aggression (psychological, economic, or physical), it gives meaning, valuation, and resignification to experience in the past, from this, it is that it retrieves your identity empowerment, motivational and entrepreneur in the productive area.
\end{abstract}

Keywords: identity, gender, resilience, empowerment

\section{Introduction}

How is the identity of a woman who has been through violence for many years constructed? What are the factors that contribute to become and develop a resilient being? How can we empower women so that they have a place and a fair distribution of resources (material and symbolic) and that they are recognized by themselves?

The identity is a process that is constructed through speech and social practices. It is essential to understand the phenomenon of violence against women, since the process of construction of identity is always given within a framework of social representations which, in the case of the battered woman, is part of a long historical way of inequality of gender, founded in the androcentrism and sustained from the patriarchate.

It is not easy to speak of violence, since it is a phenomenon of countless edges, it may be for this reason, it is the most serious problem causing us to when you want to restrict it and try to qualify it or quantify it, as if the violence was only "a” and had "entity".

Our reality is plagued by violence, at the level of events and actions, such as armed conflict, crime, kidnappings for ransom and terrorism, among others, as well as to level of certain logics and mechanisms, such as impunity, the handling of information, certain functionality of myths and stereotypes, empty, "violent", among other laws.

All this, without a doubt, establishes a fertile ground so that through certain joints can develop, for example, the phenomenon of domestic violence.

This phenomenon is complex and multifaceted. One of the most difficult and challenging tasks is to break

Angélica Flores González, Ph.D., Social Service Department, Autonomous University of Baja California.

Sandra Carina Fulquez, Ph.D., Laboratory of Basic and Applied Psychology, Autonomous University of Baja California. 
down the different forms of violence to better understand its characteristics, causes, and consequences. Violence can be categorized according to different variables: individuals who suffer violence: women, children, youth, elderly, and disabled; the agents of violence: gangs, drug traffickers youth; the nature of the aggression: psychological, physical, sexual, financial, and environmental; the reason of aggression: political, racial, economic, instrumental, and emotional; and the relationship between the subject who suffers and which exerts violence: relatives, couples, friends, known-called domestic violence—and that occurs between subjects that are not related in this way, called social violence. Domestic violence usually takes place within the confines of the home, while social violence usually occurs in the street or public places and is, in consequence, more visible.

Violence against women is any act of violence based on membership of the female gender, which has or may have as a result harm or physical, sexual, or psychological suffering to women, as well as the threats of such acts, coercion or arbitrary deprivation of liberty, whether occurs in public as in private. The difference between this type of violence and other forms of aggression and coercion is that, in this case, the factor of risk or vulnerability is the mere fact of being a woman.

In Mexicali Valley, a rural-urban region with significant agricultural export economy, border with California and Arizona is an important social problem and few data indicates that measures taken by the legal system are insufficient. From different fields, it comes out an attempt to address the phenomenon of gender-based violence, considering that they are different types of factors that contribute to the emergence of this fact. Sometimes, it tends to justify violence against women by appealing to possible mental imbalances of the offender; however, we believe that there is, along with the psychological factors of the victim and the aggressor, another type of social factors that significantly influence the violent actions.

However, the objective of this work consists in reflecting on the factors that have an impact on the resilience and contribute to give a new meaning sense of identity in women, in terms of overcoming personal and productive

Some of the issues around which we develop this work are: How to build the process of identity in battered women and what their identity elements? How same these women and what is the definition given by others? How does the recognition game? How would like to be seen by others? In what aspects are identified and what is the difference between?

\section{The Concept of Identity}

The gender role socialization occurs through learning, this being the medium to transmit values, attitudes, and rules. In this sense, since the childhood gender stereotypes are developed, and a boy or a girl, crystallizes in the mode in which the parents consider how should behave. Here the learning process plays an essential role. From the social cognitive theory, it can be said that gender identity is constructed through the cognitive processing of experiences, learning about social roles for each sex and norms are to dominate the type of behavior typical of their sex. This is how acts according to the socially pre-established scheme. The gender role is developing along the evolutionary development of the child and children begin to imitate and to choose models, so that at the age of 5-6 conform to types of masculinity and femininity; at age 8, the position is more liberal and sexual differences are increased to 10 years. Later, in adolescence, they establish a personal identity and stereotypes are accepted. If we differentiate by gender we can highlight, on the one hand, girls, to be near his mother, learn the features of personality, attitudes, values and maternal roles to affective and personal ties. 
Thus, the role of feminine gender is constituted by stereotypes as passive, tender, submissive, compliant, vulnerable, and dedicated to the care of others. Women who fit these stereotypes perceived the men as signs of power and authority, and the small child is identified with the role and traits of the father. Masculinity means denying the relationship with the mother and has this universal element of the male role. The result will be social roles abstract and impersonal. Men associated are stereotyped behaviors, competitive, aggressive, high degree of demand for success, wisdom, courage, and knowledge control. It is then when adapted to the gender stereotype good man perceives women as weak and hostile.

Therefore, we can conclude that, in the construction of gender and socialization processes, the family is the benchmark that new members are to be identified. Adults influence the processes of identity both the boy and the girl. Very small parents transmit gender patterns and treat the children differently from girls.

However, we cannot ignore that there is another factor of interest in this process: enthusiasm media that promote the configuration of gender stereotypes, exhibiting both images that socially devalues the woman as images that reinforce the qualities of power, productive work, decision-making, and self-reliance in men.

Ultimately, socially it prepares men for a dominant role, and if they do not consequent, they seek to obtain it by force; for them, violence is a means of controlling women. The socialization makes men a role based on the power, authority, and in the domain; and women in purely female roles as sweetness, and the expression of the emotions. Hirigoyen (2006) has stated about Pierre Bourdieu: "Everything is courageous, respectable; worthy of admiration is of order masculine, while weak, insignificant or unworthy belongs to the female register".

Identities are constituted within and not outside representation and are related with the tradition and the invention of tradition, we can say that the identity is a representation through which subjects are recognized if, classified the world and are located in it. It is a social construction, therefore, it will have disputes of meaning, determining elements, use of power, delimitation, exclusion, identification, and social imaginary.

Therefore, the identity is a relational concept, which to build will need the presence of another which settles an approximation or similarity, but also a distinction.

One of the important elements in the configuration of the identity is recognition games. These are not anything other than power relations with the attributions of identity imposed on the other. To establish through a relational system, we can say that the identity is internally and externally.

In the case of a group of women struggling to assert their rights, for example, another can do external group censorship and this absorbs it according to the force having these games. The more consolidated is the group; more force will have to impose their identity.

Awards games can be instituted through the language, the media, at the legal level through laws, among others, reflecting the social recognition for example having this group of women.

It is important to clarify that there is no identity, but there are many identities. It is to say that the same subject has the ability to assume different identities, depending on their position and according to the situations with which it has to face.

\section{Resignification of the Identity of Gender From Resilience Capacity}

Suarez (2004) has mentioned a term that comes from physics, the ability of a material to recover its original shape after stay under high pressures. By analogy, in the human or social sciences, people began to use this word to designate the human faculty that allows people leaving secure and safe experiences and adverse situations. 
According to Beltran (2006) and Werner (1989), investigations carried out from the 1970s onwards, were the certainty that it is possible to promote resilience as a mechanism of prevention in mental health and social ability to cope with the adversities of life.

Now, to get successful results when working the resiliency, as well as keep in mind which is not an absolute or stable concept, it must take into account intrinsic factors (internal) and extrinsic (external) the own individual. On the one hand, internal factors are the different reactions of people in different circumstances, personal characteristics associated with the temperament, personality, character and tolerance for frustration, the mode of conflict resolution, cognitive experience, and assertiveness, also, referring to having a sense of humor, being sociable, having high self-esteem and internal control problems, seeing positively the future, being flexible and adapt, among others. The external factors are those situations that may or not generate stress, relating to the characteristics of the environment of the person: family, social, relationship with peers, etc.. It could also be the environment values, encourage people and education is promoted, there are relationships of support, responsibilities are shared, promoted the achievement of goals, among others. Then, you could say that resilience is a set of features that result from positive interaction between the personal and environmental component of a person.

With the implementation of the project on resilience and its pillars (based on the internal and external factors) in the group of mutual support, we have tried to provide a new way for the interpretation of the different situations that have lived the women in situation of violence, allowing this way that they focus on their potential, according to the environment in which they live and not in its limitations. The importance of this process is having the option to see themselves as owners of your life, with the possibility of taking decisions aimed at the goals proposed.

According to Vanistendael (1995), resilience has components and pillars that are essential for determining whether a person is resilient. Two of these components are resistance: occurring against the destruction in order to protect the own integrity under pressure, and the ability to build positively: which occurs despite difficult circumstances. Another important component is the self-esteem, because it is based on the large number and variety of thoughts, feelings, experiences, experiences, and feelings that have accumulated over the life of the people.

In practice, it has been seen that self-esteem is a cornerstone for the development of resilience, since it is from this self-love that is a person more "easy" through adverse situations, without being influenced by what happens to its around.

\section{Resilient Personal Characteristics (Wolin, Sybil \& Wolin, Steven, 1999)}

Introspection: is to have the ability to ask itself and given an honest answer; taking a meaning of stress situations.

Independence: is the ability to establish boundaries between oneself and adverse environments, showing the ability to maintain emotional and physical distance without reaching isolated.

Ability to relate: is the ability to establish satisfactory and intimate bonds with other people, swinging with the own need of sympathy and willingness to provide others.

Initiative: is to have positive outlook setting goals possible to achieve, in relation to their abilities and with the environment.

Sense of humor: is the balance between a cheerful behavior (playful), the environment and the critical 
capacity of the person, to sizing problems.

Creativity: the ability to create order, beauty and purpose from the chaos and disorder.

In childhood the creation is expressed in the games, which are the ways to reverse the loneliness, fear, rage and despair.

Morality: is the desire of a personal life satisfactory, pleasant and with inner wealth.

The women of the mutual support group who have had the opportunity to participate in the project of resilience, have been able to identify some of these features in their personal lives such as humor, resistance, the ability to relate, the importance of improving their self-esteem. To recognize them has been able to attribute more power to its capabilities and downplaying their limitations, feeling capable of coping with the difficulties that they face.

According to Indaburu (2004) Rogers (1951) has referred to important components such as emotional support, which represents the changes that come with a positive attitude, a comprehensive climate of sympathy and stimulation, as well as social support networks, understood as a process of permanent building both at the individual level as collective, considering it as an open system, whose dynamic exchange between its members enables the potentiation of the resources you have. In this system, there should be understanding, tolerance, respect and acceptance.

Moreno (2002) has found that the above issues are related somehow the concept of social capital, because it is a concept that synthesizes a set of values that are generated as a social whole, ability to work in groups and organizations to achieve common goals. It is a natural resource that increases when used, contributing to create social value and optimize the benefits of physical and human capital. What is an important factor of development is based on cultural roots and social virtues of individual.

It is also from the social capital that you can create and promote strong enough social and emotional support networks to develop people and resilient communities. In mutual support groups so that intervention is complete, in addition to working in internal (such as self-esteem, mood, etc.) aspects, also works on factors community as community participation, economic diversity, leadership, knowledge of laws and rights (human and women), among others, through training conducted by the team of coordinators. In this way, it contributes to the formation of resilience in a complementary manner, thus emphasizing the importance of work both at the internal factors and external people.

But also to develop the aspects mentioned above-either individually or in a group-it is important to build on the culture because it is a powerful instrument that shapes the personality of men and women through their prejudices, myths, customs, beliefs, and traditions, which operate as parameters of behavior and that influence social representations and the way of reasoning of the members of a community.

You can use these aspects are positively to create appropriate behaviors favoring women, but also to the social whole.

Now, one of the behaviors learned culturally, is precisely the violence and takes this community shape especially in the first years of life, the family, the school. But if it is learned and not instinctive, you can unlearn it is.

\section{Discussion}

As a professional intervention strategy, our team decided to form a self-help group, under the joint coordination of a psychologist and a sociologist, both knowledgeable of the subject. The criteria to attend the 
group are: (1) being female; (2) becoming a victim of family violence; (3) voluntarily attend; and (4) having an interview with sociologist and psychologist.

One of the characteristics of this group is its openness and flexibility. To get a woman victim of violence joins the same, previous individual interviews. A rather heterogeneous group in terms of the ages of women, education, civil status, and socio-economic level of the same is forming in this way.

Professional intervention techniques used are various. To begin with, in every meeting used relaxation techniques, so that women can disconnect from their everyday problems and in this way contact with themselves, with their emotions, with their bodies, and with they being more intimate. For this is the room in the dark, made to lie on the floor, shown them that they have to stay with your eyes closed, puts on a very soft background music and begins to work with breathing exercises and visualization. The exercise lasts approximately 25 minutes.

Another technique used is the reading of texts, from which are allusive to the subject of family violence to stories, poems, reflections, and even cards that they themselves write or have written at some time. The aim is that each can think through these texts, as a message, learning, or moral.

Also it used the technique of brainstorm of ideas which they are bringing through a phrase that serves as a trigger. The music is very important, since not only is it used for the exercises of relaxation and visualization, but also to do some body expression exercises. In addition, of course, it used interview technique in depth. The meetings are very intense and emotional, given that there women tell their stories of life, moving and disturbing.

Some women at the beginning cannot tell their stories and this is mainly due to two reasons: feeling shame or going through an emotional crisis that only allows them to express themselves through the tears. However, others have the urgent need to be heard, so they begin to tell their stories of life without any difficulty.

\section{Process of Construction of Identity}

We would see how same women in the group and what is the definition given by others. An interesting question in the group is the fact that the self-definition of these women is fully conditioned and determined by the definition attributed by their partners. The fact that the aggressors permanently exercised psychological violence towards them, assuring them on a daily basis over many years that are calibrated, whores, old, fat, mad, sick, useless, guilty, among other epithets, ends these self-convinced women victims of abuse that this is as well. The speech of the aggressor is building the identity of the victim in a subtle and unconscious way. The victim internalizes this speech and plays it in his own daily practice as if it were what the speech said it was.

The over determination on these women, that the aggressor carried out through this everyday speech, is reinforced and justified by the lattice of myths, beliefs and speeches socially constructed around the female gender. The subordination of women has been historically conditioned by this definition attributed by the male, which has its base in patriarchy and the androcentrism. The male is strong, who dominates the head of the family, and does not cry or show emotions. The woman is attentive, obedient, sacrificed, gives everything for others, follows her husband "until death do part them", sometimes literally, waiting to "perform" a prince charming.

This is all an order symbolic, ideological, socio-cultural, and historically constructed from the power attributed to men and which allows them to reproduce a model of thought installed on politics, religion, philosophy, science, the economy, and social media, that on a daily basis playing as "natural" image of women 
less than men, pleasure object reduced only to your body or just certain parts of the same, housewife, cooking, being in charge of the children, secretary, always employed male or located behind it. The phrase "behind every great man is a great woman" reflects this situation of historical subordination of women.

Our self-help group women are not alien to this whole process of naturalization of the subordination of women. On the contrary, this social imaginary is reinforced by the cycle of domestic violence and the kind of emotional bond that these women have with their partners of offenders. In this sense, the discourse that constructs identity does not come a stranger, but the person who they have chosen as a partner to form a family, to have children, for "life", as they repeat and repeat in the group.

How realizes game of recognition by the other in these women? If in the everyday life of any person the other censorship is significant and affects one way or another, in the case of these women victims of abuse, the other is strongly reduced to the mere presence of the offender, since they are in a situation of isolation and are at the mercy of their partners. One of the characteristics of domestic violence is that the aggressor gradually isolates women, first of their social environment and after her family of origin and his closest friends, in order to control and easily manipulate their victim.

The aggressor is only another, the only reference for the recognition of these women. The recognition game boils down to a game of manipulation, since unlike the processes of construction of identity which sets this game of recognition between subject, in the case of situations of violence in general, there is a relationship from subject to subject, but from subject to subject, marking this a clear distinction and peculiarity that distinguishes this type of system of social relations. This is not sufficiently developed in the theory and deserves a more comprehensive analysis, enabling you to have more elements for understanding and professional intervention in this field of reality for the future.

The self-help group is necessary to other references that contrast this image that women have of themselves and this is where our work becomes necessary in this process of deconstruction and reconstruction of identity, intervene in this everyday life and life experience, to-from here-help to modify it.

How would like to be seen by others these women? To go to the self-help group, these women are showing a desire to change their situation. The instance appears as a place of containment, a support, a means to find out or solution to your problem. The group is for these women the only space where they can speak of themselves and recognize each other as women. It is for the vast majority the only place that they have to interact with others, given the situation of isolation that are and that we described above.

Fear is a significant identity element in the women of the group. He is not only fear, but many fear or, better yet, fear of many different things. This point unites them, but also is different.

From where originate these fears? In general, originate from their life stories; these women have one of the features of the syndrome of abused women, which is learned helplessness. It is a situation where women learn to be helpless, as is taught that she is weak, vulnerable, inferior, incapable and that only can defend someone strong and superior. This strength and superiority are embodied in the figure of the male: the father, the brother, and the couple. They are responsible for raising their children in this order, making the difference between his sons and his daughters' women, thus reproducing the learned model.

This state of learned helplessness generates feelings of guilt, fear and low, self-esteem. These three elements - the guilt, fear, and low self-esteem—paralyzed so the woman victim of violence, that makes her unable to see a way out and break the circle of violence where. These three elements interact between if feeding each other, and therefore, constitute the basement where it is held and crystallizes the catatonic state and 
numbness that is, inert and unarmed, the battered woman.

The blame is another significant identity element in the women in the group. As with fear, women express different feelings of guilt.

Low self-esteem is another significant identity element in the women of the group. As indicated in its etymology, the word self-esteem refers to the assessment that one has of itself. This assessment is built from the look the other and look towards one's self from childhood and usually in a household. The stories told by the women of the group realize that they have come to form partner with an image quite poor themselves, which it reinforces and further degraded in the couple's relationship with insults, humiliation and qualifiers who suffer on a daily basis.

As a result of this psychological and emotional violence, many women have tried to commit suicide when they reach the limit lower self-esteem, when they believe that their life no longer has any value or felt. For many women, death is the only way that comes for your situation.

In our case, the women in the group build its "nosotras (ourselves)" in the group, looking to be seen simply as women, not as objects of domination and manipulation by their partners, not as calibrated, whores, old, fat, mad, sick, useless, or guilty.

\section{Mechanisms of Cohesion as a Configurative Element of Identity in the Group}

A mechanism of cohesion that arises in the group is the explicit agreements of watch is during holiday recess of the work team, and swap their addresses in order to not lose the contact between them and have someone with whom to speak and to whom appeal if you feel sad, alone or in a threatening situation. This mechanism has a sense of protection and solidarity network and demonstrates the need to continue to exist as a group, regardless of the circumstantial physical place that unites them until that time. It is a mechanism that expresses the sense of belonging and identification as a group.

Another mechanism of cohesion is that each member, including coordinators, expressed with words their experience in the group and count what served you, what are your wishes for the future, what she learned during this time, what things you would like to change and what things, and how they feel and all that want to say at this time. This mechanism shows the sincerity and the degree of affection generated in the group.

During the process of recovery of self-esteem and overcoming of fear and guilt, women show their mood with various symbols: clothes, makeup, hairstyles, attitudes, walk, smile, the tone of voice, the job search, the start of courses, among others. These symbols express the new look that acquire respect to themselves and others: see as a woman and value as a human being. In addition, they reflect that there is a new definition and recognition as constituent elements of the self.

\section{Identification and Differentiation in the Group}

Identification is approaches and intersections, emphasizing the processes of similarities that articulate ties of solidarity and partnership based on the recognition of a common origin or shared with other individuals or groups, or with some ideal characteristics, but which in turn implies a set of differences, discursive work, marking, fixation of symbolic boundaries, and border effects production.

The group of women provides an identification process based on their common origin as battered women and characteristics shared in terms of discourse and the attitudes of their respective aggressors. These similarities are however different life stories that emerging from the stories. Articulated ties of solidarity and alliances among the women of the group, create a real network of mutual aid through the exchange of favors, 
medicines, clothes, or money. But also, this process of identification involves differences, for example in what makes the continuity of the partner link. Some women expressed their desire to continue holding the link or retrieve it. Others, however, want to dissolve it definitively.

Another difference is that while some expressed the desire not to have any kind of relationship with another man anymore, others are betting the couple, love, thinking about remaking their lives one day. In fact, during the course of the group process some women engage in new relationships with other couples.

\section{Empowerment}

How can empowerment be defined? The methodology that we use-experiential methodology—is designed to activate within the person aspects of cognitive, emotional and attitudinal to auto generate that change, because it is not something that can be imposed or granted, but must move the person inside. We believe that it is a learning process, with a way to go and a starting point, although we do not believe have arrival point since it works as a spiral that is developing new levels of awareness and exercised a power of resonance in immediate contexts, as we have seen. It has a subjective dimension that makes it very important, called "power in".

According to Sharma (1991-1992), it is the power that allows developing self-esteem and the confidence to change the situation of subordination. We believe that we must redefine aspects as the value, self-efficacy. The term empowerment refers to a range of activities from individual self-affirmation to the collective resistance, and mobilizing to challenge power relations. It is thus a process oriented to change the nature and direction of the systemic forces that marginalize women and other sectors at a disadvantage in a given context.

It is multidimensional, composed of a range of interdependent factors. According to Kabeer (1999), there are three fundamental dimensions for empowerment: agency, resources, and achievements. "Resources" are running the conditions to make possible the empowerment, the "agency" refers to the same process, the capacity of action of women, and the "achievements" refers to the results of the process. Mora's (2006) has found that each of these dimensions is elements of the same process, so we must analyze them interdependently, by implications that have with each other.

Rowlands (1995) has found that it works on different group scales: personal, interpersonal, or both. Finally, we intend to activate change processes that generate a new notion of power, opposed to power in "masculinizadas (masculinization)" societies, a democratic and shared power. The definitions of empowerment are not met, as well as its consequences. Advances in conceptualization have meant the pursuit of holistic empowerment strategies, and thereby have emphasized that there is no magic formula or foolproof design, that there is no single recipe or prescriptive model. Disciplinary studies (Peled, Eiskovitz, \& Enoch, 2000) show that their approaches are still sometimes ideological and prescriptive rather than descriptive and practical what constitutes a challenge continue placing under the umbrella of this approach to redefine the unequal relations between women and men to build a more just society.

\section{Conclusions}

Identity is a relational concept, and it needs the presence of another which settles an approximation or similarity, but also a distinction.

The importance should be put on resilience and empowerment in abused women.

How abused women managed to advance and empower themselves in a self-help group should be paid attention to. 
The project was seeking to recover the identity gained from a group of women in situation of violence resignifying their gender identity.

\section{References}

Beltrán, A. I. (2006). Promoción de la resiliencia mediante juegos en niños maltratados (Doctoral dissertation, Catholic Bolivariana University).

Flores, A. (2012). Seeds of life project: Identity, gender violence and sustainability (Unpublished manuscript, Support Program to Women of the Mexicali Valley).

Hirigiyen, M. F. (2006). Madres maltratadas. Contextos, Barcelona: Los mecanismos de la violencia en la pareja. Paidós.

Indaburu, M. G. (20004). Factores protectores de resiliencia en niños y jóvenes trabajadores (Doctoral dissertation, Catholic Bolivariana University).

Kabeer, N. (1999). Resources, agency, achievements: Reflections on the measurement of women's empowerment. Development and Change, 30, 435-464.

Mora, L. (2006). Igualdad y equidad de género: Aproximación teórico-conceptual. Herramientas de trabajo de genero para oficinas y contrapartes UNFPA

Moreno, J. I. (2002). Proyecto tutorial de capital social y liderazgo juvenil. Bolivia: La Paz.

Peled, E., Eiskovitz, Z., \& Enoch, W. (2000). Choice and empowerment for battered women who stay toward a constructivist model. Social Work, 45(1), 9-25.

Rogers, C. (1951). Client-centered therapy, its current practice, implications, and theory. UK: Constable and Robinson LDT.

Rowlands, J. (1995). Empowerment examined. Development in Practice, 5(2), 101-107.

Sharma, K. (1991-1992). Grassroots organizations and woman's empowerment. Some issues in the Contemporary Debate en Samya Shakti, 6, 28-43.

Suarez, N. (2004). Resiliencia, tendencia, perspectivas. UNL: A Buenos Aires.

Vanistandael, S. (1995). Como crecer superando los percances. B.I.C.E.: Montevideo, Uruguay.

Werner, E. E. (1989). High risk children in young adulthood: A longitudinal study from birth to 32 years. American Journal of Orthopsychiatry, 59, 72-81.

Wolin, Sybil, \& Wolin, Steven. (1999). Frame concepts (Project resilience). Retrieved from: http://projectresilience.com//frames concepts-html 